\title{
ARTICLE OPEN \\ Comparative effect of alkaline elements and calcium on alteration of International Simple Glass
}

\author{
Hélène Aréna ${ }^{1,2}$, Diane Rébiscoul ${ }^{2}$, Emmanuelle Garcès ${ }^{1}$ and Nicole Godon ${ }^{1}$
}

In the concept of deep geological repository for High Level Wastes, the chemical elements present in the media are expected to impact the long-term behavior of the glass. The effects of $\mathrm{Ca}, \mathrm{K}$, and Cs on International Simple Glass glass alteration are compared through long-term experiments (180-500 days). These elements limit glass alteration by their incorporation into the gel layer. The limiting mechanisms driving glass alteration appear to be mainly diffusive, at least during the first six months. The three cations are not equally efficient in limiting glass alteration: the effects of $\mathrm{Ca}$ are stronger than those of $\mathrm{Cs}$ and K. Multi-element experiments show that the effects of these elements are additive and proportional to the quantity of each element incorporated. When they play the role of charge compensator in the gel network, their incorporation is competitive and follows the order Ca $\gg \mathrm{Cs}>\mathrm{K}$. In addition, when $\mathrm{Ca}$ is added to the solution in excess, the quantity of elements incorporated into the gel layer is higher than the amount required for charge compensation. The incorporation of $\mathrm{Ca}$ in the gel nanopores as calcium carbonate could explain this phenomenon. These processes could slow the transport phenomena through the gel and enhance its protective properties.

npj Materials Degradation (2019)3:10; https://doi.org/10.1038/s41529-019-0072-7

\section{INTRODUCTION}

Interactions between glasses and solutions are of great interest in the field of material degradation, particularly to study the longterm behavior of high-level radioactive wastes. In deep geologic repository of high-level waste, the chemical elements present in the media (groundwater, near-field materials, metallic barriers, and the glass itself) are expected to have an impact on glass alteration.

During glass alteration, several concomitant or subsequent processes occur. First, glass hydration and interdiffusion induce ion exchange between protons from the solution and alkali from the glass, leading to a layer of hydrated glass. ${ }^{1,2}$ Simultaneously, the glass network is dissolved by the hydrolysis of the covalent bonds. As $\mathrm{Si}$ and $\mathrm{Al}$ are released from the glass, the solution reaches an equilibrium state and the rate of the hydrolysis reaction decreases. At this point, some elements ( $\mathrm{Si}, \mathrm{Al}, \mathrm{Zr}$, etc.) recondense to form a gel layer at the hydrated glass surface. Depending on its composition and porosity, this nanoporous layer may protect the underlying glass. ${ }^{3-6}$ Finally, the residual stage of alteration is controlled by the reactive diffusion of species from the glass and the solution through the hydrated glass and the gel, as well as the precipitation of secondary phases. During their formation, these secondary phases consume elements from the solution and the gel, particularly Si and Al, leading to a decrease in the protective properties of the gel. ${ }^{7,8}$ Under certain conditions, the glass alteration process may resume. This phenomenon has been observed during the precipitation of zeolites and hydrated calcium silicates. ${ }^{9}$

In our previous studies, we demonstrated that the addition of $\mathrm{Zn}, \mathrm{Mg}, \mathrm{Ni}, \mathrm{Co}$, and/or Fe to the alteration solution triggers the precipitation of secondary phases. ${ }^{10,11}$ These elements strongly increase glass alteration, and their effects are additive. The overall effect is proportional to the total concentration of these elements in solution, even when a mixture of these elements is used. Depending on the conditions, these elements can also be incorporated into the gel layer as a replacement for $\mathrm{Ca} .{ }^{12}$

The effects of $\mathrm{Ca}$ on glass alteration have been widely studied. ${ }^{13-18}$ When $\mathrm{Ca}$ is released through glass alteration or is added to the solution, it can be retained or incorporated into the gel layer. ${ }^{12,19} \mathrm{Ca}^{2+}$ can participate in gel network formation as a charge compensator for the $\left[\mathrm{AlO}_{4}\right]^{-}$and $\left[\mathrm{ZrO}_{6}\right]^{2-}$ units. ${ }^{20} \mathrm{Ca}$ can also condense via olation with the heavy elements in the gel, leading to a high degree of reticulation in the gel network. ${ }^{21}$ Under static conditions, $\mathrm{Ca}$ can act as a catalyst in the condensation reaction of silica responsible for the gel formation. ${ }^{22,23}$ Thus, the presence of $\mathrm{Ca}$ strengthens and densifies the gel network, thereby limiting the transport of water and elements through the gel layer and reducing the rate of glass alteration. ${ }^{22,23}$ In addition, some studies have demonstrated the precipitation of Ca carbonates in the pores of nanoporous silica and the altered glass gel layer. ${ }^{24,25}$

Ambient conditions, especially the $\mathrm{pH}$, can affect these processes. $^{22,26,27}$ As the $\mathrm{pH}$ decreases, Ca becomes more concentrated in the solution and is less retained/incorporated into the gel layer, which in turn loses its protective properties. At $\mathrm{pH}<11$, Ca forms metallic surface complexes, weakening the Si-O bonds and thereby favoring their hydrolysis. ${ }^{26,28}$ At a high $\mathrm{pH}$ and for long-term experiments, the main drawback is the massive formation of secondary phases such as hydrated calcium silicates. ${ }^{29-31}$ The precipitation of these secondary phases consumes silicon and maintains a high glass dissolution rate.

Alkaline elements such as $\mathrm{Cs}$ and $\mathrm{K}$ are present in nuclear glasses and/or in the environment, near-field minerals, and groundwater. While the effects of $\mathrm{Ca}$ on glass alteration are well known, ${ }^{26}$ the impacts of Cs and $\mathrm{K}$ have been poorly studied. The incorporation of $\mathrm{K}$ in the alteration layer was observed in natural

${ }^{1}$ CEA, DEN, DE2D, SEVT, LCLT, F-30207 Bagnols sur Cèze Cedex, France and ${ }^{2}$ ICSM, CEA, CNRS, ENSCM, Univ. Montpellier, Marcoule, 30207 Bagnols-sur-Cèze, France Correspondence: Hélène. Aréna (helene.arena@cea.fr) or Nicole Godon (nicole.godon@cea.fr)

Received: 9 August 2018 Accepted: 25 January 2019

Published online: 01 March 2019 
analogs, $^{32-36}$ archeological glasses ${ }^{37-41}$ and the International Simple Glass (ISG). ${ }^{4,42}$ Recently, Collin et al. ${ }^{42}$ studied gel layers formed during the alteration of ISG in Si-saturated solutions containing $\mathrm{K}, \mathrm{Cs}$, $\mathrm{Li}$, or $\mathrm{Na}$ ions at $\mathrm{pH}$ 7. $\mathrm{K}$, and to a greater extent, $\mathrm{Cs}$, were incorporated in the gel layers as replacements for $\mathrm{Ca}$. The exchange between $\mathrm{Ca}$ and alkali affects the total quantity of water inside each gel; this phenomenon is well correlated with the observed decrease in glass alteration. ${ }^{42}$

The presence of $\mathrm{K}$ or $\mathrm{Cs}$ in secondary phases formed during the alteration of nuclear glasses and obsidian have been reported. ${ }^{31,43,44}$ However, these elements are incorporated as exchangeable cations in the structure of the secondary phases. Therefore, their presence in the media alone does not trigger precipitation, and no effect on glass alteration has been observed. ${ }^{45}$ The formation of $\mathrm{K}$ or Cs carbonates is not favored during glass alteration since these minerals are highly soluble in solution.

In this work, we compare the effects of $\mathrm{Cs}, \mathrm{K}$, and $\mathrm{Ca}$ on the alteration of ISG glass to determine whether they are additive or competitive, similar to that done in our previous studies involving $\mathrm{Zn}, \mathrm{Mg}, \mathrm{Ni}, \mathrm{Co}$, and Fe. ${ }^{10-12}$ To achieve this goal, an extensive set of long-term experiments (180-500 days) was designed. The chloride salts of $\mathrm{K}, \mathrm{Cs}$, and/or Ca were added to the solution after one day of alteration in pure water at $50^{\circ} \mathrm{C}$. Two glasses were considered, ISG and its Ca-free equivalent, CJ7. ${ }^{46}$ In addition, because the composition of the gel layer is strongly affected by the $\mathrm{pH}$, experiments at fixed $\mathrm{pH}$ values were also conducted.

\section{RESULTS}

Scientific approach

First, to compare the effects of Ca originating from the glass with those of $\mathrm{Ca}$ added to the solution, the alteration of ISG in pure water (ISG test) was compared with that of CJ7 glass altered in $\mathrm{CaCl}_{2}$ solution $\left(4 \times 10^{-3} \mathrm{~mol} \mathrm{~L}^{-1}\right.$ - CJ7-Ca test). This concentration was chosen to be representative of the maximum amount of $\mathrm{Ca}$ available in solution after one month of ISG glass alteration at a residual rate. ${ }^{47}$

To study the effects of $\mathrm{Cs}$ and $\mathrm{K}$, and to compare them with those of $\mathrm{Ca}, \mathrm{CJ} 7$ glass was altered in $\mathrm{CsCl}$ or $\mathrm{KCl}$ solutions $(4 \times$ $10^{-3} \mathrm{~mol} \mathrm{~L}^{-1}$ - CJ7-Cs and CJ7-K tests, respectively). This concentration fell in the range in which these elements are present in the media (i.e., the glass and the groundwater of the geological repository). To determine whether the effects of these elements were additive or competitive in nature, a multielemental experiment (CJ7-KCsCa test) was performed. In this experiment, all three elements were added together with an elemental concentration of $1.3 \times 10^{-3} \mathrm{~mol} \mathrm{~L}^{-1}$ each. The cumulative concentration $([\mathrm{K}]+[\mathrm{Cs}]+[\mathrm{Ca}])$ in the $\mathrm{CJ} 7-\mathrm{KCsCa}$ experiment was the same as the mono-elemental concentration used in the CJ7-K, CJ7-Cs, and CJ7-Ca tests, i.e., $4 \times 10^{-3} \mathrm{~mol} \mathrm{~L}^{-1}$.

In addition, the effects of $\mathrm{K}$ and $\mathrm{Cs}$ on ISG glass were studied in the ISG-K and ISG-Cs experiments, respectively. In these experiments, two of the three elements were present together: $\mathrm{KCl}$ or $\mathrm{CsCl}$ were introduced to the solution at a concentration of $4 \times$ $10^{-3} \mathrm{~mol} \mathrm{~L}^{-1}$, and Ca was provided by ISG glass alteration. The results of these were also compared with those of the ISG-Ca experiment, in which ISG was altered in the presence of $1 \times 10^{-2}$ mol $\mathrm{L}^{-1}$ of $\mathrm{CaCl}_{2}$ in the solution. This test was initially conducted to compare the effects of $\mathrm{Fe}, \mathrm{Mg}$, and $\mathrm{Ca}$ on ISG glass alteration, and the detailed results are reported a previous paper. ${ }^{12}$ All these tests were conducted without controlling the $\mathrm{pH}$.

Finally, two ISG glass alteration tests were conducted at fixed $\mathrm{pH}$ values. The $\mathrm{pH}$ was expected to have a strong impact on the behavior of the elements and on their concentrations in solution. In the ISG-pH6.9 and ISG-pH7.6 tests, the pH was maintained by the addition of $\mathrm{HCl}$ or $\mathrm{NaOH}\left(10^{-3}\right.$ to $\left.1 \mathrm{~mol} \mathrm{~L}^{-1}\right)$. The measured $\mathrm{pH}$
Table 1. References and characteristics of each experiment. All experiments were conducted at $50^{\circ} \mathrm{C}$, and the first element addition was carried out after one day of alteration in pure water

\begin{tabular}{|c|c|c|c|c|c|c|c|}
\hline & \multirow[t]{2}{*}{ Name } & \multirow[t]{2}{*}{ Glass } & \multicolumn{2}{|c|}{ Element(s) present } & \multicolumn{2}{|c|}{$\begin{array}{l}\text { [element] in } \\
\text { solution }\end{array}$} & \multirow[t]{2}{*}{$\begin{array}{l}\mathrm{pH} \\
\left(50^{\circ} \mathrm{C}\right)\end{array}$} \\
\hline & & & in solution & $\begin{array}{l}\text { from } \\
\text { glass }\end{array}$ & $\begin{array}{l}10^{-3} \\
\mathrm{~mol} \mathrm{~L}^{-1}\end{array}$ & $\begin{array}{l}1^{-3} \mathrm{~g} \\
\mathrm{~L}^{-1}\end{array}$ & \\
\hline \multirow{6}{*}{$\begin{array}{l}\text { Glasses } \\
\text { without } \mathrm{Ca}\end{array}$} & CJ7-K & $\mathrm{CJ} 7$ & $\mathrm{KCl}$ & - & 4 & 156 & Free \\
\hline & $\mathrm{CJ} 7-\mathrm{Cs}$ & CJ7 & $\mathrm{CsCl}$ & - & 4 & 532 & Free \\
\hline & $\mathrm{CJ} 7-\mathrm{Ca}$ & $\mathrm{CJ} 7$ & $\mathrm{CaCl}_{2}$ & - & 4 & 160 & Free \\
\hline & \multirow{3}{*}{$\begin{array}{l}\text { CJ7- } \\
\mathrm{KCsCa}\end{array}$} & \multirow[t]{3}{*}{ CJ7 } & $\mathrm{KCl}$ & - & 1.3 & 51 & \multirow[t]{3}{*}{ Free } \\
\hline & & & $\mathrm{CsCl}$ & & 1.3 & 173 & \\
\hline & & & $\mathrm{CaCl}_{2}$ & & 1.3 & 52 & \\
\hline \multirow{6}{*}{$\begin{array}{l}\text { Glasses with } \\
\mathrm{Ca}\end{array}$} & ISG-K & ISG & $\mathrm{KCl}$ & $\mathrm{Ca}$ & 4 & 156 & Free \\
\hline & ISG-Cs & ISG & $\mathrm{CsCl}$ & $\mathrm{Ca}$ & 4 & 532 & Free \\
\hline & ISG-Ca & ISG & $\mathrm{CaCl}_{2}$ & $\mathrm{Ca}$ & 10 & 400 & Free \\
\hline & ISG & ISG & - & $\mathrm{Ca}$ & - & - & Free \\
\hline & $\begin{array}{l}\text { ISG- } \\
\text { pH6.9 }\end{array}$ & ISG & - & $\mathrm{Ca}$ & & & 6.9 \\
\hline & $\begin{array}{l}\text { ISG- } \\
\text { pH7.6 }\end{array}$ & ISG & - & $\mathrm{Ca}$ & & & 7.6 \\
\hline
\end{tabular}

variations and corrections are given in Supplementary Information 1. The target $\mathrm{pH}$ values were 6.5 and $7.5\left(\right.$ at $50^{\circ} \mathrm{C}$ ); however, the average $\mathrm{pH}$ values obtained were 6.9 and 7.6 , respectively. In this study, the word "solubility" is used for chemical elements $(K, C s$, $\mathrm{Ca}$ ), even though it is normally applied to phases. The solubility of a chemical element means the solubility of the phase controlling the concentration of the element in solution. The names and the characteristics of each experiment are listed in Table 1.

\section{Alteration kinetics and $\mathrm{pH}$ evolution}

The normalized boron mass losses $(\mathrm{NL}(\mathrm{B}))$ and $\mathrm{pH}$ are shown as a function of time in Fig. 1. For the sake of clarity, Fig. 1 has been divided into several parts, in each of which only two to five experiments are compared. However, the results of all experiments are also plotted together in single figures in Supplementary information 2. From the $\mathrm{NL}(\mathrm{B})$ values, the alteration rates during several time periods were calculated (Fig. 1g, h).

Firstly, we studied the effect of $\mathrm{Ca}$ origin and $\mathrm{pH}$, through experiments CJ7-Ca, ISG, ISG-pH6.9, and ISG-pH7.6. In pure water, glass alteration induces the release of alkali and boron, resulting in $\mathrm{pH}$ values of up to $\sim 9$ for ISG at $50^{\circ} \mathrm{C}$ and $\sim 8.7$ for $\mathrm{CJ} 7$ at $90^{\circ} \mathrm{C} .{ }^{46}$ The stabilization is due to the buffer effect of boron acid/borate, and the composition of the glass impacts the final $\mathrm{pH}$ value. When ISG was altered at lower fixed $\mathrm{pH}$ values (ISG-pH6.9 and ISG $\mathrm{pH} 7.6)$, the amount (NL(B), Fig. 1a) and rate (Fig. 1g, h) of glass alteration were higher than in the free-pH reference test (ISG). Thus, higher glass alteration quantities and rates were correlated with lower $\mathrm{pH}$. This result can be attributed firstly to an increase in the hydration/interdiffusion rate and secondly, to a lower retention of $\mathrm{Ca}$ in the gel layer. In the fixed-pH tests, the $\mathrm{NL}(\mathrm{Ca})$ values were much lower than the $\mathrm{NL}(\mathrm{B})$ values (Supplementary information 1). Thus, when the fixed $\mathrm{pH}$ was decreased, the glass exhibited more alteration because the Ca was less retained in the alteration layer, and the alteration rate drop occurred later.

When $\mathrm{Ca}$ was added directly to the solution during the alteration of CJ7, the Ca-free glass (CJ7-Ca test), the $\mathrm{NL}(\mathrm{B})$ values, alteration rate, and $\mathrm{pH}$ (Fig. $1 \mathrm{a}, \mathrm{b}, \mathrm{g}$ and $\mathrm{h}$ ) were lower than those observed when the Ca originated from the glass alteration (ISG test). As will be discussed later, this difference could be related to the availability of $\mathrm{Ca}$. When $\mathrm{Ca}$ is added to the solution, a large amount is immediately available, whereas when it is provided by the glass, the glass network must first be hydrolyzed to make $\mathrm{Ca}$ available. 

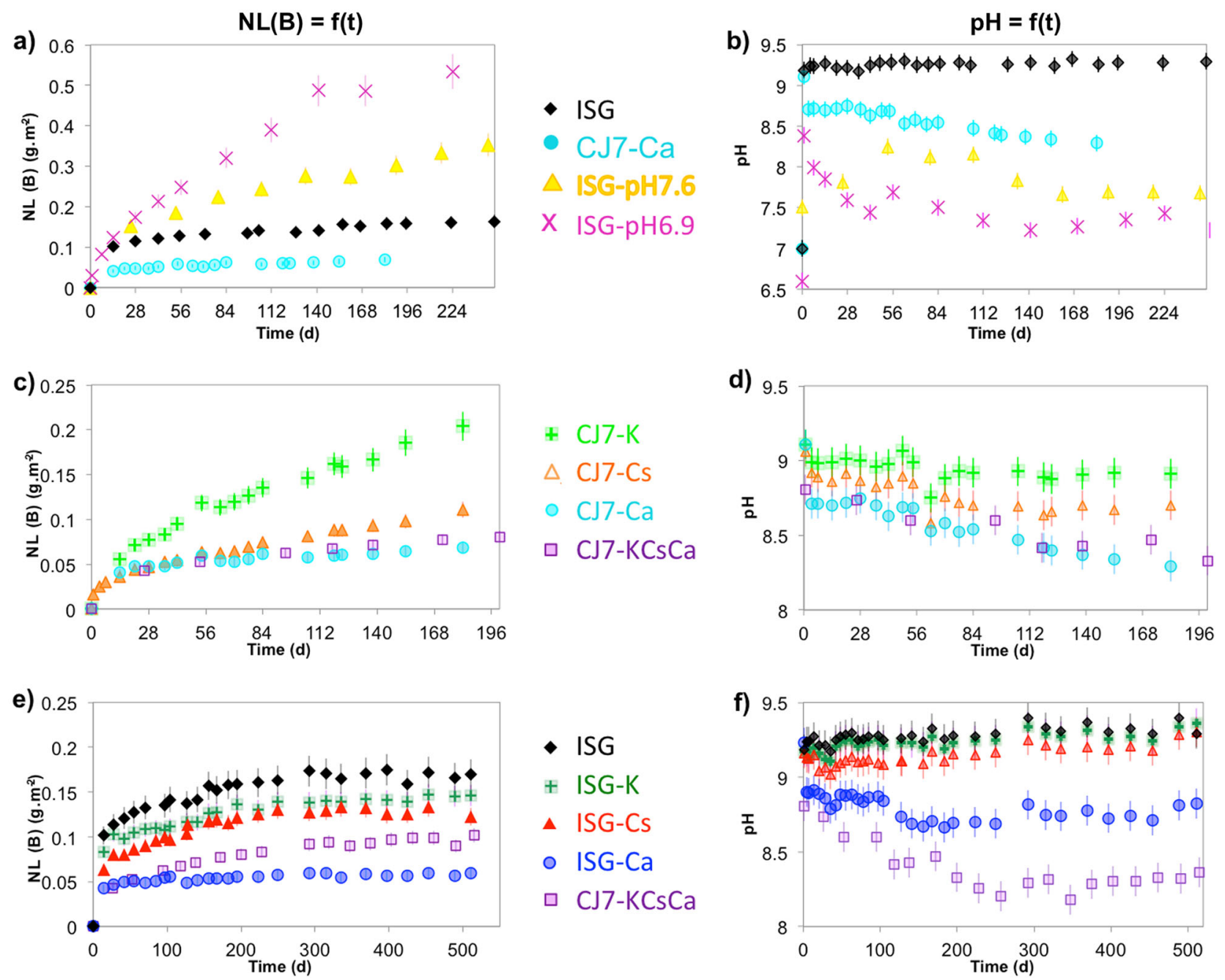

- ISG

+ ISG-K

- ISG-CS

- ISG-Ca

口 CJ7-KCsCa

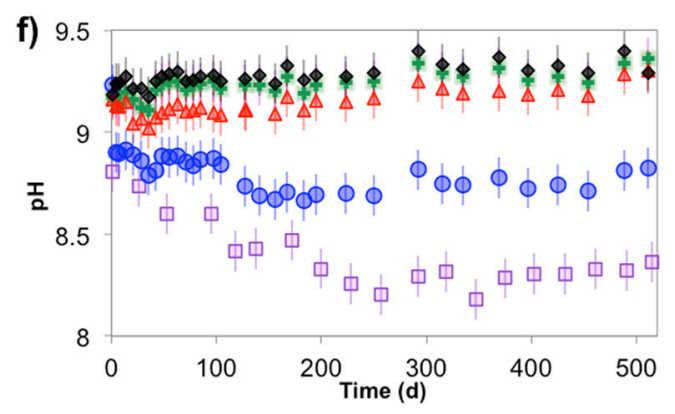

g)

\begin{tabular}{|c|c|c|c|}
\hline & \multicolumn{3}{|c|}{ Alteration rate $\left(\mathrm{g} \cdot \mathrm{m}^{-2} \cdot \mathrm{d}^{-1}\right)$} \\
\hline Time range (d) & $100-200$ & $150-300$ & $180-454$ \\
\hline ISG-pH6.9 & $2.2 \times 10^{-3}$ & $8.6 \times 10^{-4}$ & \\
\hline CJ7-K & $7.5 \times 10^{-4}$ & & \\
\hline ISG-pH7.6 & $6.8 \times 10^{-4}$ & $8.7 \times 10^{-4}$ & \\
\hline CJ7-Cs & $3.8 \times 10^{-4}$ & & \\
\hline ISG-K & $2.9 \times 10^{-4}$ & & $3.8 \times 10^{-5}$ \\
\hline ISG & $2.5 \times 10^{-4}$ & $1.5 \times 10^{-4}$ & $4.0 \times 10^{-5}$ \\
\hline ISG-CS & $2.4 \times 10^{-4}$ & & $3.4 \times 10^{-5}$ \\
\hline $\mathrm{CJ} 7-\mathrm{KCsCa}$ & $2.0 \times 10^{-4}$ & $1.3 \times 10^{-4}$ & $7.3 \times 10^{-5}$ \\
\hline CJ7-Ca & $1.4 \times 10^{-4}$ & & \\
\hline ISG-Ca & $7.9 \times 10^{-5}$ & & $1.1 \times 10^{-5}$ \\
\hline
\end{tabular}

h)

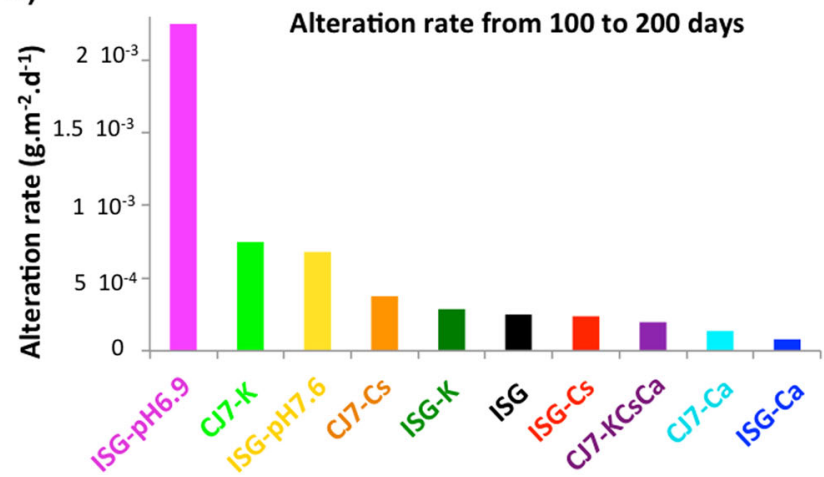

Fig. $1 \mathrm{NL}(\mathrm{B})$ (left) and the $\mathrm{pH}$ (right) as a function of time. $\mathbf{a}$, $\mathbf{b}$ show a comparison of the effect of Ca added to the solution (CJ7-Ca) and leached from the glass at free pH (ISG) and fixed pH (ISG-pH6.9 and ISG-pH7.6). c, d present the results of the experiments in which K, Cs, Ca, or $\mathrm{K}+\mathrm{Cs}+\mathrm{Ca}$ were added to CJ7 (experiments CJ7-K, CJ7-Cs, CJ7-Ca, and CJ7-KCsCa, respectively). e, f present the results of the multielemental experiments ( $\mathrm{Ca}+\mathrm{K}, \mathrm{Cs}+\mathrm{Ca}, \mathrm{K}+\mathrm{Cs}+\mathrm{Ca}$; experiments ISG-K, ISG-Cs, and CJ7-KCsCa, respectively) and the experiment ISG-Ca in which the concentration of $\mathrm{Ca}$ in the solution was higher. $\mathbf{g}$ Alteration rates calculated during different time ranges and $\mathbf{h}$ histogram of the alteration rates calculated between 100 and 200 days

Secondly, we studied the effect K, Cs, and/or Ca through the comparison between the elements and between the glasses. In the presence of $\mathrm{K}, \mathrm{Cs}$, and/or Ca, the $\mathrm{NL}(\mathrm{B})$ values for CJ7 (Fig. 1c) and ISG (Fig. 1e) and their alteration rates (Fig. 1g, h) were lower than in pure water. In both cases, the effects of Ca were stronger than those of Cs and K, partly because the rate drop occurred sooner. Comparing the mono-elemental ISG experiments (ISG-K, ISG-Cs, ISG-Ca) with those using CJ7 (CJ7-K, CJ7-Cs, CJ7-Ca), the NL (B) values and glass alteration rates were lower for CJ7, except for the experiment CJ7-K. However, in pure water, CJ7 was significantly more altered than ISG, as has been reported in several studies. ${ }^{46,48}$ 

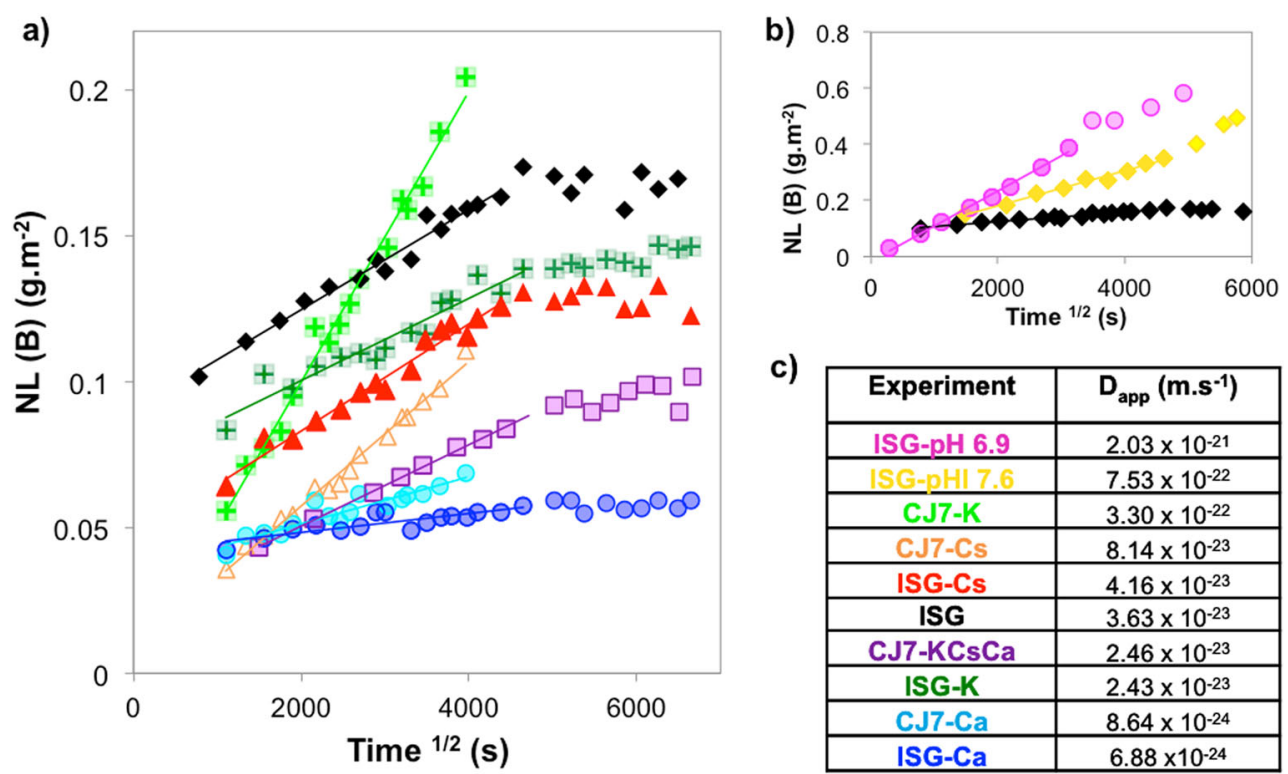

c)

\begin{tabular}{|c|c|}
\hline Experiment & $\mathbf{D}_{\text {app }}\left(\mathbf{m . s}^{-1}\right)$ \\
\hline ISG-pH 6.9 & $2.03 \times 10^{-21}$ \\
\hline ISG--jH 7.6 & $7.53 \times 10^{-22}$ \\
\hline C.J7-K & $3.30 \times 10^{-22}$ \\
\hline CJ7-Cs & $8.14 \times 10^{-23}$ \\
\hline ISG-Cs & $4.16 \times 10^{-23}$ \\
\hline ISG & $3.63 \times 10^{-23}$ \\
\hline CJ7-KCsCa & $2.46 \times 10^{-23}$ \\
\hline ISG-K & $2.43 \times 10^{-23}$ \\
\hline CJ7-Ca & $8.64 \times 10^{-24}$ \\
\hline ISG-Ca & $6.88 \times 10^{-24}$ \\
\hline
\end{tabular}

Fig. 2 a, b NL(B) as a function of $t^{1 / 2}$. c Calculated apparent diffusion coefficient $D_{\text {app }}$ for each experiment

When all three elements were added together (CJ7-KCsCa), the results were very similar to those obtained for the experiment CJ7Ca (Fig. 1c, g, h). The NL(B) values and alteration rates were much lower than those for ISG in pure water or even in the presence of $\mathrm{K}, \mathrm{Cs}$, or Ca (ISG-K, ISG-Cs, and ISG-Ca). As will be discussed later, this suggests that the effects of these elements are additive.

For CJ7, the $\mathrm{pH}$ remained relatively stable for the first 50 days of alteration, and decreased slightly afterwards (Fig. 1d). In the multielemental experiment CJ7-KCsCa, the $\mathrm{pH}$ values were similar to those of CJ7-Ca, and finally stabilized after 300 days (Fig. 1d). The $\mathrm{pH}$ values for ISG quickly became stable, and were higher than those observed for CJ7 (Fig. 1f). For both glasses, experiments involving $\mathrm{Cs}$ resulted in higher $\mathrm{pH}$ values than the Ca experiments, but lower ones than the $\mathrm{K}$ experiments. The $\mathrm{pH}$ values followed the same order as the $\mathrm{NL}(\mathrm{B})$ values; therefore, the alteration of a greater amount of glass induced a higher $\mathrm{pH}$. This result can be explained by the release of alkali into the solution, which increased the $\mathrm{pH}$.

\section{Predominant processes}

During the first 200 days of all the experiments, the $\mathrm{NL}(\mathrm{B})$ values increased linearly with the square root of time (Fig. 2a, b). Therefore, according to Fick's second law, the glass alteration was driven by a diffusive process during this period (see the methods section). The apparent diffusion coefficients $D_{a p p}$, which represent the diffusion rate of water (or other species) through the gel layer, were calculated at $50^{\circ} \mathrm{C}$ and are presented in the table in Fig. 2-c. These coefficients ranged from $10^{-25} \mathrm{~m}^{2} \mathrm{~s}^{-1}$ to $10^{-21} \mathrm{~m}^{2} \mathrm{~s}^{-1}$; these values fell within the range for the diffusion of water in glass. ${ }^{17}$ Moreover, the $D_{\text {app }}$ coefficients followed the same order as the NL (B) and alteration rate values. Therefore, this diffusion process also controlled glass alteration at longer times. In the fixed-pH experiments, the coefficient $D_{\text {app }}$ increased with a decrease in $\mathrm{pH}$. This could be attributed to enhancement of the hydration/ interdiffusion process and/or a decrease in Ca retention/incorporation, leading to a less protective gel layer.

After 200 days, glass alteration kinetics (NL(B)) no longer followed the relationship with the square root of time, and instead tended towards stabilization. This suggested a change in the ratelimiting processes, which were similar regardless of which cation (s) were added to the solution.

\section{Cations concentrations}

Figure 3 presents the concentrations of the cations measured before the monthly additions as a function of time. The setpoint values of the monthly additions are indicated by the dashed horizontal lines. Data points below the setpoint value indicate that the element was still being consumed, while stabilization of the data near the setpoint indicates that element consumption had stopped.

As shown in Fig. 3a, when the pH was fixed (experiments ISGpH6.9 and ISG-pH7.6), the Ca concentrations in the solution were much higher than that in the free-pH test (ISG). In addition, the $\mathrm{Ca}$ concentrations increased regularly and then stabilized. This stabilization may be due to Ca reaching saturation in the solution under these conditions.

When Ca was added to the solution (ISG-Ca and CJ7-Ca), the values of the $\mathrm{Ca}$ concentrations were irregular, making their interpretation difficult (Fig. 3b). This variability could be due to calcite or other Ca carbonate precipitation/dissolution phenomena in solution and/or in the gel layer. Indeed, as indicated in Supplementary information 3 , if the concentration is high enough, calcite could precipitate at the $\mathrm{pH}$ of the experiments.

When $\mathrm{Cs}$ or $\mathrm{K}$ was added to the solution during ISG alteration, the element was partly consumed during the first two to three months, after which the consumption stopped (Fig. 3c). When K, $\mathrm{Cs}$, or Ca was added to the solution during CJ7 alteration, the element was partly consumed each month throughout the entire experiment (Fig. $3 \mathrm{~d}$ ). The concentration remaining in solution at the end of each month slightly increased, but the consumption did not stop. Finally, when all three elements were added together (Fig. 3e), the Ca concentrations were lower than the those of Cs, which in turn were lower than those of $\mathrm{K}$. At the end of the experiment, only $\mathrm{Ca}$ was still being consumed, and the concentration remaining of $\mathrm{K}$ exceeded the setpoint value.

\section{Elemental incorporation/retention ratios}

The consumption of $\mathrm{K}, \mathrm{Cs}$, and $\mathrm{Ca}$ from the solution was used to calculate the ratio $R_{X}$ between the quantity $\left(n_{x}\right)$ of the element retained and/or incorporated into the gel layer and the $\mathrm{NL}(\mathrm{B})$ (Eq. 1). The word "incorporation" refers to elements added to the solution and integrated into the gel layer assuming that no secondary mineral precipitation occurs at the gel surface, and the word "retention" refers to Ca provided by the ISG alteration that is 

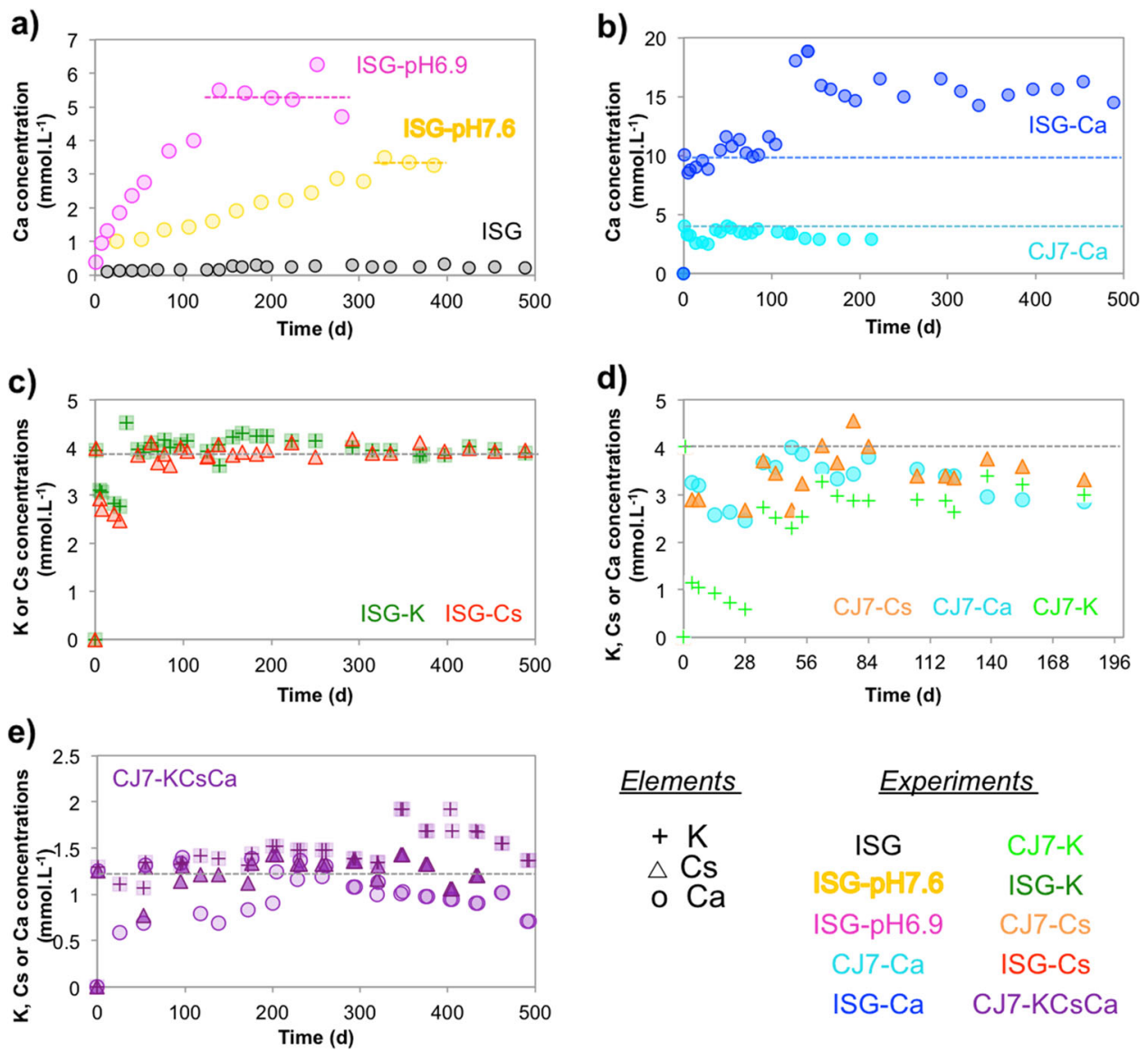

Elements

$+\mathrm{K}$

$\triangle \mathrm{Cs}$

o $\mathrm{Ca}$
Experiments

ISG

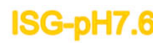

CJ7-K

ISG-pH6.9

ISG-K

CJ7-Ca

CJ7-Cs

ISG-Ca
ISG-Cs

CJ7-KCsCa

Fig. $3 \mathrm{Ca}, \mathrm{Cs}$, and $\mathrm{K}$ concentrations in solution before the monthly additions as a function of time in selected experiments. Horizontal lines are included as a guide for the eyes to highlight the data stabilization in a, and to show the setpoint value for the monthly addition in each experiment in b-e.

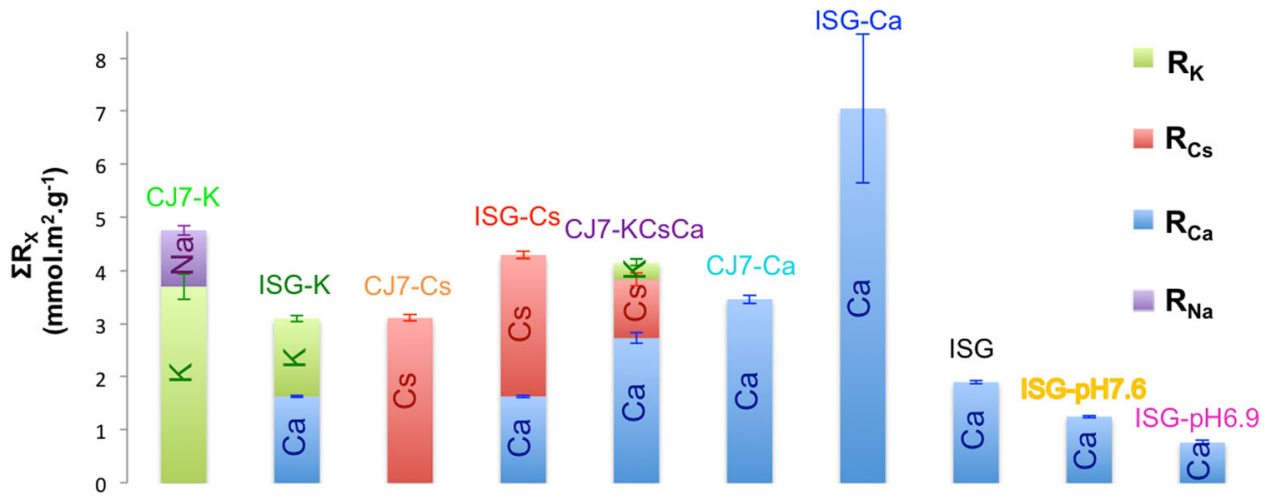

Fig. 4 Proportions of the elements incorporated/retained in the gel layer represented by the ratio $R_{X}$ between the quantity ( $n_{X}$ ) of the element retained and/or incorporated into the gel layer and the NL(B) value. The error bars are based on the standard deviation calculated for the $R_{X}$ values during the last 100 days

not released into the solution, and is therefore retained in the gel layer.

$R_{X}=\frac{n_{X}}{N L(B)}$

where $X=K, C s$. or $C a$, and $n_{X}$ is the quantity of the element $X$ incorporated or retained in the gel layer ( $\mathrm{mmol}$ ).

The Na present in both the CJ7 and ISG glasses could behave as a charge compensator. In all experiments except CJ7-K, Na was released congruently with $B$, indicating that it was not retained in the alteration layer. Therefore, $\mathrm{Na}$ was only considered in the calculations for experiment ISG-K. Because the $R_{X}$ values remained constant as a function of time (Supplementary Information 4), an average value of $R_{X}$ was selected for each element of each experiment (Fig. 4).

As presented in Fig. 4, $\mathrm{R}_{\mathrm{Ca}}$ was higher for experiment CJ7-Ca than for experiment ISG. Therefore, the incorporation of $\mathrm{Ca}$ from the solution into the CJ7 gel layer was higher than the retention of $\mathrm{Ca}$ in the ISG gel layer. In experiments with a fixed pH (ISG-pH6.9 and ISG-pH7.6), $\mathrm{R}_{\mathrm{Ca}}$ was much lower than in the free-pH ISG 
reference test (ISG). Therefore, Ca retention increased with the $\mathrm{pH}$. As discussed above, the Ca consumption data for experiments CJ7-Ca and particularly, ISG-Ca, are highly variable and difficult to interpret. Nevertheless, when $\mathrm{Ca}$ was provided via monthly additions, its concentration in the solution was high enough to enable a high $\mathrm{R}_{\mathrm{Ca}}$ and thereby high incorporation of $\mathrm{Ca}$ into the gel layer.

The Ca retention was equal (same $\mathrm{R}_{\mathrm{Ca}}$ ) in the experiments ISG-K and ISG-Cs, but a much greater proportion of Cs was incorporated in ISG-CS than $K$ in ISG-K $\left(R_{C S}>R_{K}\right)$. In the multi-elemental experiment CJ7-KCsCa, the $\mathrm{R}_{\mathrm{x}}$ values followed the order $\mathrm{Ca}>\mathrm{Cs}$ $>\mathrm{K}$. The $\mathrm{R}_{\mathrm{Cs}}$ values were similar in the CJ7-Cs and ISG-Cs experiments, but lower in the experiment CJ7-KCsCa. The $\mathrm{R}_{\mathrm{K}}$ values varied greatly depending on the experiment: in the presence of $\mathrm{Cs}$ and $\mathrm{Ca}(\mathrm{CJ} 7-\mathrm{KCsCa})$, barely any $\mathrm{K}$ was incorporated, while its incorporation was greater in the presence of Ca (ISG-K test) and even more when $\mathrm{K}$ was alone in the solution (CJ7-K test).

Moreover, in all the experiments except ISG-pH6.9 and ISG$\mathrm{pH7.6}$, the sum of the $\mathrm{R}_{\mathrm{X}}$ values was higher than the $\mathrm{R}_{\mathrm{Ca}}$ value for ISG alteration in pure water. This indicated that ISG and CJ7 can incorporate a greater amount of the tested elements $(\mathrm{K}, \mathrm{Cs}$, and/or $\mathrm{Ca}$ ) into their gel layer than the quantity of Ca provided by ISG alteration.

\section{DISCUSSION}

The Discussion section is divided into five parts. First, we discuss the $\mathrm{pH}$ dependence, followed by the imapct of the origin of $\mathrm{Ca}$. Afterward the effects of $\mathrm{K}, \mathrm{Cs}$ and $\mathrm{Ca}$ are compared in terms of quantity and efficiency, and we determine if their effects were additive or competitive in nature. Finally, we discuss the quantity of cations required for charge compensation.

The results reported in this study confirmed that the $\mathrm{pH}$ is a key parameter in glass alteration. In static conditions, when the $\mathrm{pH}$ decreased (through deliberate adjustment of the solution $\mathrm{pH}$ or passively due to the glass alteration process), glass alteration increased. Similar results were reported for ISG glass alteration at $90^{\circ} \mathrm{C}$ and $\mathrm{pH}$ values ranging from 7 to $9 .{ }^{48}$ Two explanations for this phenomenon can be proposed.

The first is that the hydration/interdiffusion and diffusion reactions are favored when the $\mathrm{pH}$ decreases. Several studies ${ }^{5,49-51}$ have demonstrated that in silicon-saturated solutions (in which the hydrolysis process is highly disfavored), glass alteration increases as the $\mathrm{pH}$ decreases. Under these conditions, the predominant processes driving glass alteration are the hydration/interdiffusion and diffusion reactions. These processes are usually predominant at the very beginning of the alteration, and also occur during the residual stage of alteration., 5 ,49-51

The second is that the solubility of $\mathrm{Ca}$ in solution increases as the $\mathrm{pH}$ decreases (Supplementary information 3). Therefore, $\mathrm{Ca}$ is less retained in the gel layer, reducing the protective effect of the gel. The rate drop was less intense, leading to an increase in the amount of altered glass. ${ }^{3}$ In the experiments ISG-pH6.9 and ISG$\mathrm{pH7.6}$, after the $\mathrm{Ca}$ concentration in the solution reached a certain value, it stabilized and the glass alteration slowed. After this point, the $\mathrm{Ca}$ retention increased, making the gel layer more protective. The value at which the Ca concentration stabilizes depends on the $\mathrm{pH}$ and may follow the trend of Ca solubility in the solution depending on the phases involved in the experimental system (an example is given using calcite in Supplementary information 3).

Additionally, although no secondary phases were observed on the altered glass samples, it should be noted that $\mathrm{pH}$ has also strongly affects the precipitation of secondary phases. The precipitation of smectites has been reported in similar experiments involving ISG glass in the presence of $\mathrm{Zn}, \mathrm{Mg}, \mathrm{Ni}, \mathrm{Co}$, or Fe. ${ }^{10-12}$ The precipitation of smectites decreases the $\mathrm{pH}$ by consuming hydroxyl ions; when the $\mathrm{pH}$ is low enough, the precipitation is inhibited. At this point, other elements such as $\mathrm{Zn}$,
$\mathrm{Ni}, \mathrm{Fe}$, or $\mathrm{Mg}$ can be incorporated into the gel layer as a replacement for the $\mathrm{Ca}$, whose solubility in solution increases due to the $\mathrm{pH}$ decrease. ${ }^{11,12}$

Regardless of its origin, i.e., via the addition of Ca to solution or the diffusion of $\mathrm{Ca}$ out of the glass, the Ca had the same overall effect on glass alteration: it limited glass alteration by its incorporation/retention into the gel layer, thereby increasing the protective properties of the layer. However, this effect was stronger when $\mathrm{Ca}$ was added to the solution (CJ7-Ca) than when it was provided by glass alteration (ISG). In experiment CJ7-Ca, the $\mathrm{pH}$ values were lower than those in experiment ISG; thus, the interdiffusion and diffusion processes must have been enhanced, and the solubility of $\mathrm{Ca}$ in solution must have been higher. Despite this, the $N L(B)$ values were lower. The Ca incorporation ratio in the CJ7 gel layer was almost twice the retention ratio of Ca in the ISG gel layer (Fig. 4). Therefore, the CJ7-Ca gel layer was more protective, and the alteration rate drop was greater and/or occurred earlier.

Several hypotheses can be suggested to explain these results. Firstly, Ca can play two roles in the gel layer. When it is provided by the glass, Ca can be incorporated into the gel network as a former and/or as a charge compensator for the $\left[\mathrm{AlO}_{4}\right]^{-}$and $\left[\mathrm{ZrO}_{6}\right]^{2-}$ units. When it is added in the solution, it can be incorporated into the gel layer both as a charge compensator and as nano-precipitates in the gel nanopores. The probable presence of dissolved carbonates in the solution may favor the incorporation of Ca through the precipitation of calcium carbonates in the gel nanopores. This type of precipitation is more strongly favored in confined media than in the bulk solution. ${ }^{52}$ It could induce pore clogging, which would limit the transport of water and other species through the gel, thereby limiting the glass alteration. This hypothesis is supported by the work of Rebiscoul et al., ${ }^{24}$ who demonstrated the presence of a carbon gradient from the solution to the glass associated with $\mathrm{Ca}$ enrichment in the gel, and suggested the presence of calcium carbonates into the gel layer. ${ }^{24}$ When $\mathrm{Ca}$ is only provided by glass alteration, the precipitation of Ca carbonates into the nanopores is less probable; therefore, the quantity of $\mathrm{Ca}$ in the gel layer is lower.

Secondly, in most of the experiments, the sum of the $R_{X}$ values was higher than the $R_{C a}$ value obtained in the experiment ISG. This result shows that the gel layer formed during the ISG experiment was capable of incorporating more cations than the amount of $\mathrm{Ca}$ that would be provided by its alteration based on its composition. Moreover, the amount of Ca supplied by ISG glass alteration in pure water is limited by the hydrolysis of the network. This situation was different in the CJ7-Ca experiment, in which the quantity of $\mathrm{Ca}$ available in solution was largely sufficient to compensate for all $\left[\mathrm{AlO}_{4}\right]^{-}$and $\left[\mathrm{ZrO}_{6}\right]^{2-}$ units present in the gel network.

Finally, when the Ca is provided by the glass (ISG test), its availability is driven by the hydrolysis of the glass network and $\mathrm{Ca}$ recondensation to participate in the gel network. ${ }^{3}$ When Ca was added directly to the solution (CJ7-Ca test), although the first addition was made after one day of alteration in pure water, the Ca was immediately available in a large and sufficient quantity.

All these explanations are supported by the $D_{\text {app }}$ values obtained from the ISG and CJ7-Ca experiments (Fig. 2). The $D_{a p p}$ value was higher when Ca originated from the glass (ISG-test) than when it was added to the solution (CJ7-Ca test). Moreover, when a large excess of $\mathrm{Ca}$ with regard to the amount required to compensate the charges in the gel (ISG-Ca) was present in the solution, $D_{\text {app }}$ was lower. This may be due to the precipitation of Ca carbonates limiting the transport of species in the gel.

The addition of $\mathrm{K}, \mathrm{Cs}$, and/or Ca limited the alteration of both CJ7 and ISG. These elements were incorporated/retained in the gel layer, enhancing its protective properties. However, although these elements had the same effect, their incorporation/retention differed in quantity and efficiency. 
The amount of $\mathrm{K}$ incorporated was reduced in the presence of $\mathrm{Ca}$ (experiment ISG-K) and even further reduced in the presence of $\mathrm{Cs}$ and $\mathrm{Ca}$ (experiment CJ7-KCsCa) compared to their absence in experiment CJ7-K. In contrast, the incorporation of Cs was not affected by the presence of $\mathrm{Ca}$ and/or $\mathrm{K}$ (experiments CJ7-Cs, ISG$\mathrm{Cs}$, and $\mathrm{CJ} 7-\mathrm{KCSCa}$ ). As expected, in the gel layer, the retention of Ca from the ISG glass was lower when $\mathrm{K}$ or Cs were present in the solution (experiments ISG-K and ISG-CS) than in pure water (experiment ISG). In experiment ISG-Cs, this lower Ca retention can be explained by the lower $\mathrm{pH}$ and therefore higher Ca solubility in the solution. However, in experiments ISG-K and ISG, the $\mathrm{pH}$ values were similar. Therefore, it was the incorporation of $\mathrm{K}$ into the gel layer rather than the $\mathrm{pH}$ conditions that limited the $\mathrm{Ca}$ retention. Thus, the presence of $\mathrm{K}$ and $\mathrm{Ca}$ affected the incorporation/retention of the other element, but Cs was not affected. When all the three elements were added to the solution (experiment CJ7-KCsCa), the amount of each element incorporated followed the order $\mathrm{Ca} \gg \mathrm{Cs}>\mathrm{K}$. The much higher incorporation of $\mathrm{Ca}$ could be explained by its role as a charge compensator/network former and its possible participation in calcium carbonate precipitation.

The alkali $\mathrm{Na}$ was also present in the system. As shown in the work of Gin et al. ${ }^{46}$ which is shown in Supplementary information 5 , when CJ7 glass is altered in pure water, $\mathrm{Na}$ is not released congruently with $\mathrm{B}$; the $\mathrm{NL}(\mathrm{B})$ is twice the $\mathrm{NL}(\mathrm{Na})$. Some of the $\mathrm{Na}$ is retained in the gel layer as a charge compensator. On the contrary, in experiments CJ7-K, CJ7-Cs, and CJ7-Ca, Na is released more congruently with $\mathrm{B}$. Thus, the incorporation of $\mathrm{K}, \mathrm{Cs}$, or $\mathrm{Ca}$ in the gel layer occurs at the expense of Na retention.

Thien et al. ${ }^{53}$ showed that $\mathrm{Na}$, which acts as a charge compensator into the gel layer, is immediately replaced by $\mathrm{Mg}$ when this element is added in the solution. Similarly, Debure et al. ${ }^{54}$ reported that when both $\mathrm{Ca}$ and $\mathrm{Mg}$ were added to the solution during the alteration of CJ7 glass, more $\mathrm{Ca}$ than $\mathrm{Mg}$ was incorporated. All these cations are exchangeable, depending on their affinity.

Therefore, the amount of cations incorporated/retained in the gel layer followed the order $\mathrm{Ca} \gg \mathrm{Cs}>\mathrm{K}>\mathrm{Na}$. This order does not follow the trend suggested by the properties of the ions in solution. According to Ohtaki et $\mathrm{al}^{55}{ }^{55} \mathrm{Ca}^{2+}$ is the most hydrated ion on this list ( 8 water molecules), and due to its thick hydration shell, has the largest hydrated radius. Therefore, it has the lowest self-diffusion coefficient and is the least mobile of the ions considered in the present study. Nevertheless, Ca was the mostincorporated element. This could be explained by the possible precipitation of calcium carbonates into the gel nanopores.

To evaluate the efficiency of the incorporation/retention of each element, we considered the slope of the total quantity of the element mobilized as a function of $\mathrm{NL}(\mathrm{B})$ (Supplementary Information 6-a). A higher slope corresponds to a lower $\mathrm{NL}(\mathrm{B})$ value for the same amount of incorporated/retained element. For both series of glasses, the slopes were lower with $\mathrm{Cs}$ than with $\mathrm{Ca}$, but higher with $\mathrm{Cs}$ than with $\mathrm{K}$. Therefore, their efficiency in limiting glass alteration followed the order $\mathrm{Ca} \gg \mathrm{Cs}>\mathrm{K}$. In light of the fact that these elements behave as charge compensators, ${ }_{1}^{20}$ it is not surprising that $\mathrm{Ca}$ is more efficient than $\mathrm{K}$ or $\mathrm{Cs}$. The $\mathrm{Ca}$ ion is bivalent and $\mathrm{Cs}$ and $\mathrm{K}$ are monovalent; thus, one $\mathrm{Ca}^{2+}$ can compensate for two negative charges, whereas $\mathrm{Cs}^{+}$and $\mathrm{K}^{+}$can only compensate for one. In addition, one $\mathrm{Ca}^{2+}$ forms two bonds and constrains the gel network more than two $\mathrm{K}^{+}$or $\mathrm{Cs}^{+}$, thereby limiting transport through the gel layer $\left(D_{a p p}\right.$ is lower for experiments in presence of $\mathrm{Ca}$ ).

The results obtained in this study indicate that $\mathrm{K}, \mathrm{Cs}$, and/or $\mathrm{Ca}$ limit glass alteration. However, at this point, it is not clear whether the effects of these elements on glass alteration were additive or competitive. From the results of the mono-elemental experiments (CJ7-Ca, CJ7-K, CJ7-Cs, and ISG), we used linear combinations to calculate the normalized boron mass losses that would be obtained if the effects of these elements were additive (2). This calculation was successfully applied to the effects of $Z \mathrm{n}, \mathrm{Mg}, \mathrm{Ni}$, $\mathrm{Co}, \mathrm{Fe}$, and $\mathrm{Ca}$ in previous papers; ${ }^{11,12}$ the effects of $\mathrm{Zn}, \mathrm{Ni}, \mathrm{Co}, \mathrm{Mg}$, and $\mathrm{Fe}$ were found to be additive, and those of $\mathrm{Fe}, \mathrm{Mg}$, and $\mathrm{Ca}$ were competitive. Here, we took into account the differences in elemental consumption between the three cations.

$$
N L(B)_{c a l}=\sum_{X}\left(N L(B)_{X \text { mono }} * C_{X}\right)
$$

where,

$\mathrm{X}$ : Element of interest $(\mathrm{K}, \mathrm{Cs}$, or $\mathrm{Ca})$;

$\mathrm{N}(\mathrm{B})_{\mathrm{cal}}$ : Calculated normalized boron mass loss;

$\mathrm{NL}(\mathrm{B})_{X}$ mono: Normalized boron mass loss reported for each element $X$ in its mono-elemental experiment. To simulate the contribution of $\mathrm{Ca}$ in the ISG-K and ISG-Cs experiments, two cases were considered: the $\mathrm{NL}(\mathrm{B})_{\mathrm{cal}}$ from experiment $\mathrm{CJ} 7-\mathrm{Ca}$ and from experiment ISG. For experiment $\mathrm{CJ} 7-\mathrm{KCsCa}$, only the case of $\mathrm{NL}$ (B) cal from the experiment CJ7-Ca was considered, since ISG was not involved in this experiment.

$c_{X}$ : Proportion of the element $X$ in the overall quantity of elements mobilized into the gel layer, calculated from the elemental consumptions.

The results are presented in Fig. 5a.

In experiment CJ7-KCsCa, the calculated values fit well with the experimental ones. Therefore, the effects of $\mathrm{K}, \mathrm{Cs}$, and $\mathrm{Ca}$ on $\mathrm{Ca}-$ free glass were additive and proportional to their elemental consumption. In experiment ISG-K, the values calculated using the $\mathrm{NL}(\mathrm{B})_{\mathrm{Cal}}$ from experiment ISG only fit the experimental values during the first month, before the e alteration rate drop. At longer times (from day 100 onward), the best fit was obtained for the values calculated using $\mathrm{NL}(\mathrm{B})_{\mathrm{Cal}}$ from experiment $\mathrm{CJ} 7-\mathrm{Ca}$. In experiment ISG-Cs, the values calculated using $\mathrm{NL}(\mathrm{B})_{\mathrm{Cal}}$ from experiment ISG fit the experimental data well, while the values calculated using $\mathrm{NL}(\mathrm{B})_{\mathrm{Cal}}$ from $\mathrm{CJ} 7-\mathrm{Ca}$ were much lower. Therefore, to take into account the effects of the Ca from the ISG, the results calculated from the ISG experiment are more useful than those of experiment CJ7-Ca. Again, the effects of these elements seem to be additive and proportional to the quantity of element mobilized into the gel layer.

Although only Ca could be incorporated in the gel nanopores as Ca carbonates, the three cations in this study could act as charge compensators. To determine the differences in charge compensation between the ions, we calculated the $Q$ ratio, which corresponds to the quantity of positive charges $\left(n_{z+}\right)$ retained and incorporated into the gel layer divided by the altered glass percentage according to Eq. (3). In this part, all the incorporated/ retained $\mathrm{Ca}$ was taken into account, whether it acted as a charge compensator, a network former, or precipitated Ca carbonate. In experiment $\mathrm{CJ} 7-\mathrm{K}$, the release of $\mathrm{Na}$ was not congruent with that of B (see Supplementary Information 5), i.e., some of the Na was retained in the gel layer. Therefore, the positive charges of $\mathrm{Na}$ were also taken into account.

$Q=\frac{n_{z+}}{A G \%}$

In all cases except the CJ7-K and CJ7-Ca tests, after a sufficient period of time, the variation of $Q$ with time became linear and remained within in the same range (Supplementary information 6b). Therefore, the phenomena involved in all the experiments may be similar and remain stable in the long term. The average values of $Q$ are reported in Fig. $5 b$ ).

Using the compositions of the ISG and CJ7 glasses, the quantity of charge compensators needed in their gels was calculated based on one negative charge for each $\mathrm{Al}$ and two for each $\mathrm{Zr}$. The concentrations of $\mathrm{Al}$ and $\mathrm{Zr}$ in solution were too low to be detected by solution analyzes, therefore, it can be assumed that these elements were fully retained in the gel layer, probably forming $\left[\mathrm{AlO}_{4}\right]^{-}$and $\left[\mathrm{ZrO}_{6}\right]^{2-}$ units. The $Q$ values needed were 
a)
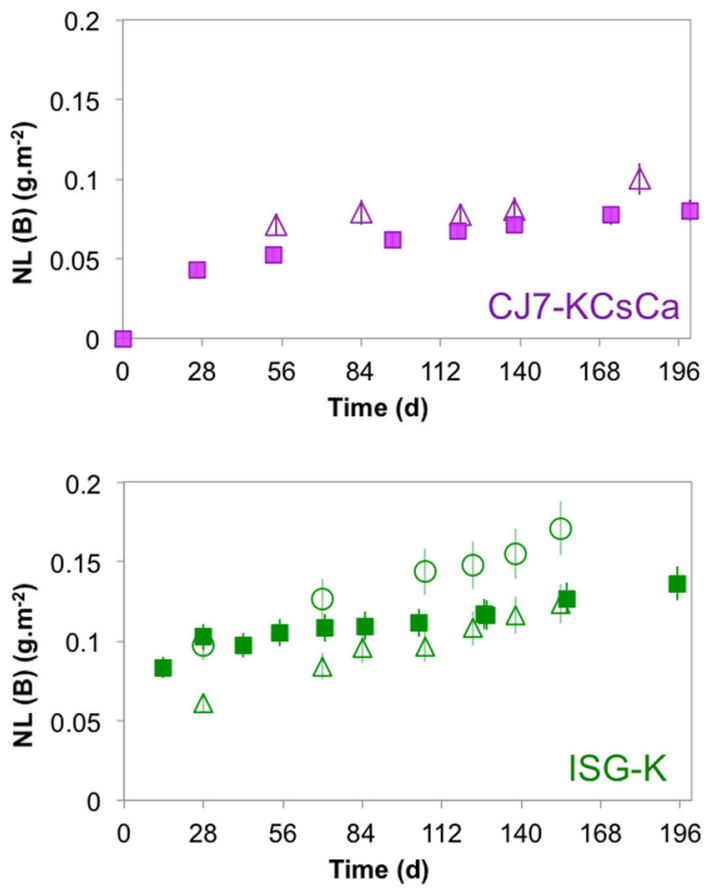

Additivity or competitivity

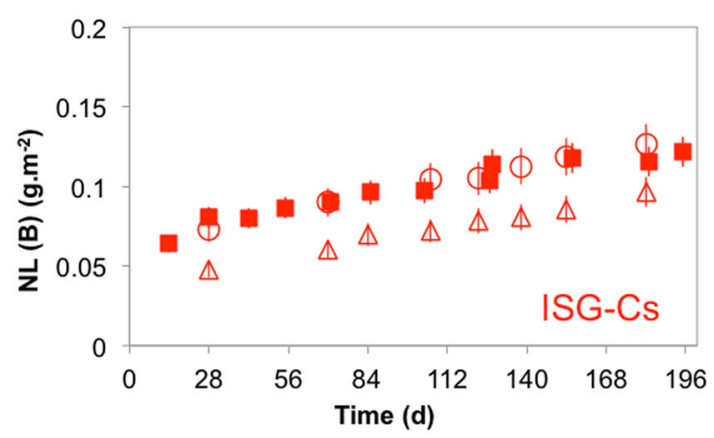

- experimental values

$\triangle$ calculated values

with $\mathrm{NL}(\mathrm{B})_{\text {cal }}$ from CJ7-Ca

o calculated values

with $\mathrm{NL}(\mathrm{B})_{\text {cal }}$ from ISG

b)

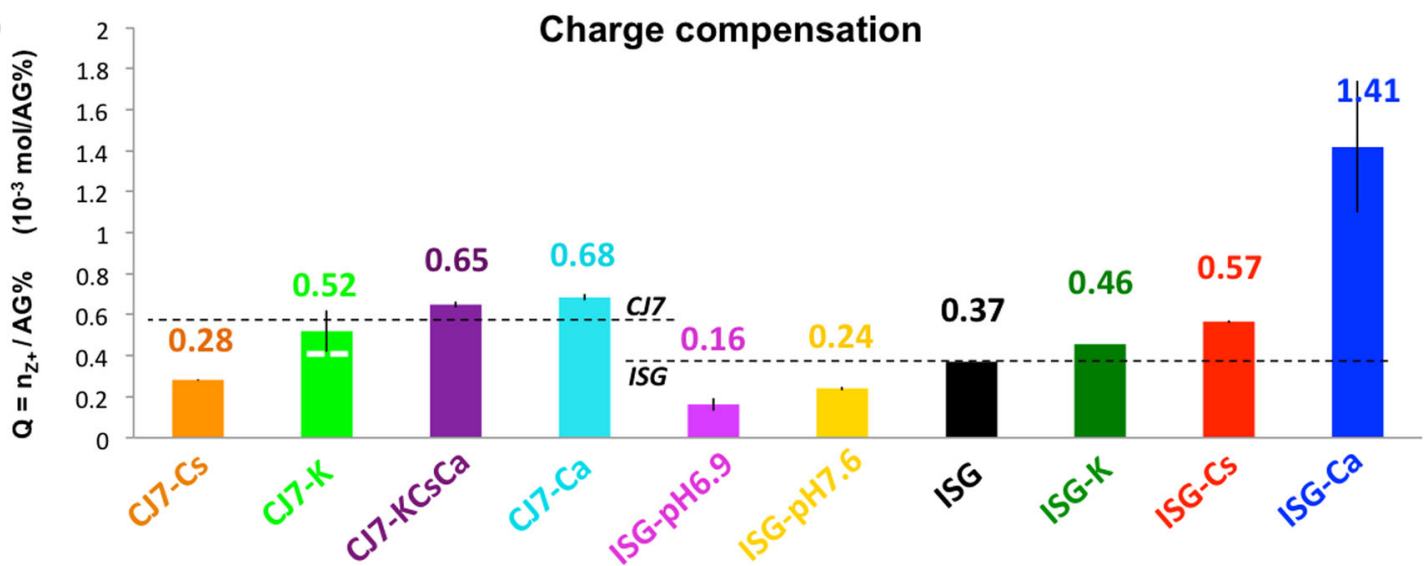

Fig. 5 a Comparison between the experimental $\mathrm{NL}(\mathrm{B})$ values and the $\mathrm{NL}(\mathrm{B})_{\text {cal }}$ values calculated using equation (2) as a function of time. $\mathbf{b} \mathrm{Q}$, the quantity of positive charges retained and/or incorporated into the gel layer for $1 \%$ of altered glass. The dashed horizontal lines represent the value of $Q$ theoretically needed to compensate for all $\left[\mathrm{AlO}_{4}\right]^{-}$and $\left[\mathrm{ZrO}_{6}\right]^{2-}$ units in the gel layer $(0.58$ for $\mathrm{CJ} 7$ and 0.39 for ISG). In experiment CJ7-K, the white line represents the $\mathrm{Q}$ value reached without taking into account the Na charges retained in the gel layer (0.34)

0.39 and $0.58 \mathrm{mmol}$ of negative charges to compensate for $1 \%$ of altered ISG and CJ7 glass, respectively. However, it should be specified that depending on the experimental conditions, the gel layers formed may be different. They may be more or less polymerized and contain non-bridging oxygens. Thus, the amount of charge compensators required can vary.

When CJ7 was altered in the presence of $\mathrm{K}$ or $\mathrm{Cs}$ and without $\mathrm{Ca}$ (CJ7-K and CJ7-Cs tests), the $Q$ values were lower than the quantity theoretically required for the CJ7 gel (0.58), even when taking into account the Na retained in the CJ7-K gel layer. The formation of $\mathrm{K}$ carbonates or Cs carbonates is unlikely, since these phases are highly soluble under the conditions of this study. Therefore, all the $\mathrm{K}$ or Cs incorporated into the gel layer should act as charge compensators. The availability of $\mathrm{K}$ or $\mathrm{Cs}$ in solution is not the limiting factor, since the amount consumed was compensated by the monthly additions. Thus, the $\mathrm{Zr}$ and $\mathrm{Al}$ atoms may have eventually changed their coordination to limit their need for charge compensators. A recent study of the Zr environment in gel layers reported a strong distortion of the Zr octahedral geometry when the gel lacks charge compensators. ${ }^{56}$

In the presence of $\mathrm{Ca}$ in solution (CJ7-Ca and CJ7-KCsCa), the $Q$ value was much higher (0.65-0.68), even higher than the amount theoretically needed (0.58). This result could be explained by the precipitation of Ca carbonates into the gel nanopores. In the CJ7$\mathrm{KCsCa}$ test, if all the $\mathrm{K}$ and the $\mathrm{Cs}$ are assumed to be mobilized as charge compensators, their incorporation represents a $Q$ value of 0.26 , which is less than the amount theoretically needed. Therefore, the incorporated Ca would consist partly of charge compensators and partly of Ca carbonate.

When ISG was altered in pure water, the $Q$ value was 0.37 . The amount of Ca retained was close to the theoretical $Q$ value of charge compensators required (0.39). As demonstrated in the ISGpH6.9 and ISG-pH7.6 tests, the increase in the Ca solubility with a decrease in $\mathrm{pH}$ leads to lower $Q$ values. In these experiments, $\mathrm{Na}$ is 


\begin{tabular}{|c|c|c|c|c|c|c|c|}
\hline Glass & Oxide & $\mathrm{SiO}_{2}$ & $\mathrm{~B}_{2} \mathrm{O}_{3}$ & $\mathrm{Na}_{2} \mathrm{O}$ & $\mathrm{Al}_{2} \mathrm{O}_{3}$ & $\mathrm{ZrO}_{2}$ & $\mathrm{CaO}$ \\
\hline \multirow[t]{3}{*}{ ISG } & $\%$ mass & 56.2 & 17.3 & 12.2 & 6 & 3.3 & 5 \\
\hline & $\%$ at & 44.3 & 35.4 & 11.8 & 4.9 & 0.8 & 2.8 \\
\hline & & \multicolumn{3}{|c|}{ Grain size: $40-63 \mu \mathrm{m}$} & \multicolumn{3}{|c|}{$\begin{array}{l}\text { BET Sa }=0.1060 \mathrm{~m}^{2} \\
\mathrm{~g}^{-1}\end{array}$} \\
\hline \multirow[t]{3}{*}{ CJ7 } & $\%$ mass & 59.1 & 18.2 & 12.8 & 6.4 & 3.5 & - \\
\hline & \%at & 45.6 & 36.4 & 12.1 & 5.1 & 0.8 & \\
\hline & & \multicolumn{3}{|c|}{ Grain size: $63-125 \mu \mathrm{m}$} & \multicolumn{3}{|c|}{$\begin{array}{l}\text { BET Sa }=0.0570 \mathrm{~m}^{2} \\
\mathrm{~g}^{-1}\end{array}$} \\
\hline
\end{tabular}

not retained in the gel layer; therefore, it can be suggested that the $\mathrm{Zr}$ and $\mathrm{Al}$ atoms changed their coordination or distorted their geometry to compensate for this lack of charge compensators. When $\mathrm{K}$ and $\mathrm{Cs}$ were added to the solution during ISG alteration (ISG-K and ISG-Cs tests), the $Q$ values increased. $\mathrm{K}$ and Cs were incorporated to complete the charge compensation, which was partly accomplished by Ca. Again, in this case the availability of $\mathrm{K}$ and Cs was not limited, therefore, the $Q$ values corresponded to the maximum amount of charge compensator needed for the gel layer formed in these conditions. As the $Q$ values reached were higher than those theoretically predicted, the gel layer may contain non-bridging oxygens requiring compensation. Finally, when Ca was provided by both glass alteration and addition to the solution (ISG-Ca), the $Q$ value reached a high value of 1.41 , which could be explained by the precipitation of $\mathrm{Ca}$ carbonates into the gel nanopores, for example.

In the present study, the effects of $\mathrm{K}, \mathrm{Cs}$, and $\mathrm{Ca}$ on the alteration of ISG and Ca-free ISG (CJ7) were studied through longterm experiments. The three elements have the same overall effect: they enhance the protective properties of the gel layer, and thereby limit the alteration of the glass. This effect is stronger when the element is directly added to the solution than when it is present in pristine glass and released by glass alteration. During ISG alteration, Ca must first be released from the pristine glass in the pore solution before being incorporated into the gel layer. In contrast, when $\mathrm{Ca}$ is added to the solution, it can be incorporated into the gel network and may also react with dissolved carbonates to precipitate as $\mathrm{Ca}$ carbonates in the gel nanopores. The $\mathrm{pH}$ conditions are a key factor influencing the Ca retention in the gel layer; lower $\mathrm{pH}$ induces lower $\mathrm{Ca}$ retention. The addition of $\mathrm{K}$ or $\mathrm{Cs}$ to the solution limits ISG alteration; these elements are incorporated into the gel layer in addition to the retained $\mathrm{Ca}$ and also as a replacement for the Ca mobilized into the solution due to the solubility of $\mathrm{Ca}$. When $\mathrm{K}, \mathrm{Cs}$, and $\mathrm{Ca}$ are added together to the solution during Ca-free ISG (CJ7 glass) alteration, they are incorporated into the gel layer; their incorporation follows the order $\mathrm{Ca} \gg \mathrm{Cs}>\mathrm{K}$. The formation of Ca carbonates could also explain this relative order. Moreover, $\mathrm{Ca}$ seems to be more efficient in limiting glass alteration than $\mathrm{Cs}$ and $\mathrm{K}$. This may be due to the bivalency of $\mathrm{Ca}^{2+}$, which makes it twice as efficient at compensating the negative charges in the gel layer. The effects of these elements are additive, but the elements are not equally efficient. The effects are proportional to the amount of each element incorporated into the gel layer. In the case of $\mathrm{Ca}$, additional incorporation as $\mathrm{Ca}$ carbonates is possible. Additional characterization would be necessary to validate this hypothesis and provide a better understanding of the processes involved. Additionally, it would be interesting to extend this study to other divalent cations present in groundwater and/or in glasses, such as barium or strontium, following the same procedure to obtain a more complete understanding of processes involved in glass alteration and gel formation. Finally, as the $\mathrm{pH}$ has an impact on
Ca retention, it could be interesting to test the addition of $\mathrm{K}$ or $\mathrm{Cs}$ at fixed $\mathrm{pH}$ values to see if they behave similarly to Ca.

\section{METHODS}

\section{Leaching experiments}

Two simple glasses based on the French SON68 inactive reference glass composition were chosen: the six-oxide ISG and its Ca-free equivalent, CJ7. ${ }^{46,57}$ The composition of these glasses is given in Table 2 .

The Ca-free ISG equivalent (CJ7) was prepared at $1400^{\circ} \mathrm{C}$ during for three hours and annealed at $450^{\circ} \mathrm{C}$ for one hour. The ISG originated from a $50 \mathrm{~kg}$ international batch. ${ }^{58}$ Both glasses were ground and sieved to recover the $40-63 \mu \mathrm{m}$ and the $63-125 \mu \mathrm{m}$ size grain fractions.

The glass powders were cleaned several times in acetone and ethanol and recovered by sedimentation to remove fine particles remaining on the surface. The specific surface areas of the powders were measured by krypton adsorption-desorption according to the Brunauer-Emmett-Teller (BET) model, and were $0.1060 \mathrm{~m}^{2} \mathrm{~g}^{-1}$ and $0.0570 \mathrm{~m}^{2} \mathrm{~g}^{-1}$ for ISG and CJ7, respectively.

Long-term static glass alteration tests were performed in PTFE reactors with a glass surface area-to-solution volume ratio $(S / N)$ of $20,000 \mathrm{~m}^{-1}$ at $50^{\circ} \mathrm{C}$. K, Cs and Ca were brought into contact with the glass via the monthly addition of chloride salts (Normapure prolabo) to the leaching solution. Each month, a maximum volume of $1.5 \mathrm{~mL}$ of solution was sampled to perform analyzes and to determine the concentration of $\mathrm{K}, \mathrm{Cs}$, and/or Ca remaining in the leachate. The sampling frequency varied slightly from one experiment to another. To compensate for $\mathrm{K}, \mathrm{Cs}$, and/or Ca consumption and for evaporation, $1 \mathrm{~mol} \mathrm{~L}^{-1} \mathrm{KCl}, \mathrm{CsCl}$ and/or $\mathrm{CaCl}_{2}$ solutions and pure water were added once a month, on the day after the last sampling and after the results of the analyzes were available. In all experiments, the renewal rate was approximately $15 \%$ vol/year.

\section{Solution analysis}

The $\mathrm{pH}$ was measured at $50^{\circ} \mathrm{C}$ before each sampling using a Metrohm 827 pH lab using NIST 7 and NIST 9 buffers for the calibration of the electrodes. The samples were then subjected to ultrafiltration through a 10,000 Dalton cutoff filter and acidified by the addition of $0.5 \mathrm{~N} \mathrm{HNO}_{3}$. The concentrations of $\mathrm{Si}, \mathrm{B}, \mathrm{Na}, \mathrm{Al}$, and $\mathrm{Zr}$ in the solution were determined from an ICP-AES analysis conducted by the "FILAB" laboratory with an analytical uncertainty of $3-5 \%$. The $\mathrm{Ca}, \mathrm{K}$, and $\mathrm{Cs}$ concentrations were measured using ionic chromatography (Metrohm Professional IC) with an analytical uncertainty of $5 \%$.

Boron was chosen as the glass alteration tracer because it is a network former that is not retained in the alteration products. From the boron concentrations $[\mathrm{B}]\left(\mathrm{g} \mathrm{m}^{-3}\right)$ obtained from the solution analyzes, the altered glass fraction \%AG and the normalized mass losses $\mathrm{NL}\left(\mathrm{g} \mathrm{m}^{-2}\right)$ were calculated using equations (4) and (5), respectively (for more details regarding the calculation method, please refer to ${ }^{46}$ and. ${ }^{22}$

$$
\begin{aligned}
& \% A G(B)_{t}=\frac{[\mathrm{B}]_{t} \vee_{b s, t}-[\mathrm{B}]_{t-1} \mathrm{~V}_{b s, t-1}}{m_{g} w t_{B}} * 100+\% A G(B)_{t-1} \\
& N L(B)_{t}=\frac{3}{S}\left(1-\sqrt[3]{\frac{100-\% A G(B)_{t}}{100}}\right)
\end{aligned}
$$

A correlation between the $\mathrm{NL}(\mathrm{B})$ and the square root of time suggests that the glass alteration is limited by a diffusion process. Because boron is a good alteration tracer, the apparent diffusion coefficient of the limiting species through the alteration layer $D_{\text {app }}$ can be calculated from the $\mathrm{NL}(\mathrm{B})$ data. Equation (6) is derived from Fick's second law and was applied between 0 and 200 days. The nature of the limiting species is still under discussion in the literature (hydrogenated species, water, silicon, etc.). In any case, the coefficient $D_{\text {app }}$ indicates the diffusion mechanism(s) and the protective nature of the gel layer.

$N L(B)=\frac{2 \rho}{\sqrt{\pi}} \sqrt{D_{B}^{\text {Fick }} \cdot t}$

In Eqs. (4) to (6), $V_{\mathrm{bs}}$ is the volume of the alteration solution before sampling $\left(\mathrm{m}^{3}\right), S$ is the specific surface area of the powder $\left(\mathrm{m}^{2} \mathrm{~g}^{-1}\right), \mathrm{m}_{\mathrm{g}}$ is the mass of glass in the experiment $(\mathrm{g}), \mathrm{wt}_{\mathrm{B}}$ is the weight fraction of boron in the glass composition, and $\rho$ is the mass density $\left(2.43 \times 10^{6} \mathrm{~g} \mathrm{~m}^{-3}\right.$ and $2.50 \times 10^{6} \mathrm{~g} \mathrm{~m}^{-3}$ for CJ7 and ISG, respectively).

The glass alteration rate $\left(r_{R}\right)$ was calculated by linear regression of four to five successive values of $\mathrm{NL}(B)$ versus time. The monthly consumption $\left(n_{c}\right.$ 
in mol) of the element $X(X=K, C s$ or Ca) was obtained using Eq. (7):

$n_{c}=n_{l, t-1}+n_{a}-n_{l, t}-n_{s}=[\mathrm{X}]_{L, t-1} V_{L, t-1}+[\mathrm{X}]_{c s} V_{c s}-[\mathrm{X}]_{L, t} V_{L, t}-\sum_{\text {month }}[\mathrm{X}]_{s} V_{s}$

where $n$ is the quantity of $\mathrm{X}$ :

present in the leachate before the addition $\left(n_{1, t-1}\right)$

added to the leachate at the beginning of the month $\left(n_{a}\right)$

remaining in the leachate after the last sampling of the month $\left(n_{1, t}\right)$

and contained in all the samples taken throughout the month $\left(n_{s}\right)$

calculated from the concentrations of the element $X\left([X], \mathrm{mol} \cdot \mathrm{m}^{-3}\right)$ and volumes $V\left(\mathrm{~m}^{-3}\right)$ of the concentrated solution $\left([X]_{\mathrm{CS}}, V_{\mathrm{CS}}\right)$, the leachate after sampling $\left([X]_{L}, V_{L}\right.$, as $)$, and the samples $\left([X]_{S}, V_{S}\right)$.

The total consumption is the sum of all monthly consumption values at time $t$ ( $\left.n_{\text {consumed, } t}\right)$.

The amount of Ca released by glass alteration and retained in the gel layer at time $t$ ( $n_{\text {Ca }}$ retained, $\left.t\right)$ can be calculated using equation (8). The amount of element $\mathrm{X}$ incorporated in the gel layer at time $t\left(n_{\mathrm{X} \text { incorporated, } t}\right)$ was calculated using Eq. (9).

$n_{\text {Ca retained }, \mathrm{t}}=\frac{\% A G_{t} \% m_{\mathrm{CaO}} m_{\mathrm{glass}}}{M_{\mathrm{Ca}}}-n_{l, t}-n_{s}$

$n_{\mathrm{X} \text { incorporated } \mathrm{t} \mathrm{t}}=n_{\mathrm{X} \text { consumed, } \mathrm{t}}=n_{\mathrm{X} \text { consumed } \mathrm{t}-1}+n_{l, t-1}+n_{a}-n_{l, t}-n_{s}$

At the end of the experiments, the altered glass powders were rinsed twice with pure water. SEM observations were conducted on the altered glass grains. In all experiments, the altered glass surface had a gel-like appearance without any secondary phase, and the altered layer was too thin to be measured or analyzed. Therefore, the solid characterization was not presented in further detail.

\section{ACKNOWLEDGEMENTS}

The authors are grateful to Emmanuelle Garcès and Géraldine Parisot for technical support. We would like to thank Renaud Podor, Marie Collin, Pierre Frugier, and Patrick Jollivet for scientific discussions. This work was funded by CEA, ORANO, and EDF.

\section{AUTHOR CONTRIBUTIONS}

H.A. was responsible for the experimental analysis and for writing the paper. N.G. and D.R. supervised the study. All the authors participated in editing of the paper.

\section{ADDITIONAL INFORMATION}

Supplementary information accompanies the paper on the npj Materials Degradation website (https://doi.org/10.1038/s41529-019-0072-7).

Competing interests: The authors declare no competing interests.

Publisher's note: Springer Nature remains neutral with regard to jurisdictional claims in published maps and institutional affiliations.

\section{REFERENCES}

1. Geneste, G., Bouyer, F. \& Gin, S. Hydrogen-sodium interdiffusion in borosilicate glasses investigated from first principles. J. Non-Cryst. Solids 352, 3147-3152 (2006).

2. Rebiscoul, D. et al. Water penetration mechanisms in nuclear glasses by X-ray and neutron reflectrometry. J. Non-Cryst. Solids 353, 2221-2230 (2007).

3. Cailleteau, C. et al. Insight into silicate-glass corrosion mechanisms. Nat. Mater. 7, 978-983 (2008).

4. Gin, S., Ryan, J. V., Schreiber, D. K., Neeway, J. \& Cabie, M. Contribution of atomprobe tomography to a better understanding of glass alteration mechanisms: application to a nuclear glass specimen altered 25 years in a granitic environment. Chem. Geol. 349, 99-109 (2013).

5. Gin, S. et al. Origin and consequences of silicate glass passivation by surface layers. Nat Commun 6, (2015).

6. Rebiscoul, D. et al. Morphological evolution of alteration layers formed during nuclear glass alteration: new evidence of a gel as a diffusive barrier. J. Nucl. Mater. 326, 9-18 (2004).
7. Frugier, P. et al. SON68 Nuclear glass dissolution kinetics: current state of knowledge and basis of the new GRAAL model. J. Nucl. Mater. 380, 8-21 (2008).

8. Crovisier, J. L., Advocat, T. \& Dussossoy, J. L. Nature and role of natural alteration gels formed on the surface of ancient volcanic glasses (Natural analogs of waste containment glasses). J. Nucl. Mater. 321, 91-109 (2003).

9. Fournier, M., Gin, S. \& Frugier, P. Resumption of nuclear glass alteration: state of the art. J. Nucl. Mater. 448, 348-363 (2014).

10. Aréna, $\mathrm{H}$. et al. Impact of iron and magnesium on glass alteration: characterization of the secondary phases and determination of their solubility constants. Appl. Geochem. 82, 119-133 (2017).

11. Aréna, $\mathrm{H}$. et al. Impact of $\mathrm{Zn}, \mathrm{Mg}, \mathrm{Ni}$ and Co elements on glass alteration: additive effects. J. Nucl. Mater. 470, 55-67 (2016).

12. Aréna, $\mathrm{H}$. et al. Impact of $\mathrm{Fe}, \mathrm{Mg}$ and $\mathrm{Ca}$ elements on glass alteration: interconnected processes. Geochim. Cosmochim. Acta 239, 420-445 (2018).

13. Smets, B. M. J., Tholen, M. G. W. \& Lommen, T. P. A. The effect of divalent-cations on the leaching kinetics of glass. J. Non-Cryst. Solids 65, 319-332 (1984).

14. Barton, J. \& Guillemet, C. Le verre, science et technologie. (EDP sciences, 2005).

15. Angeli, F., Boscarino, D. \& J-C, P. Influence of calcium on sodium aluminosilicate glass leaching. Phys. Chem. Glass. 42, 279-286 (2001).

16. Arab, M., Cailleteau, C., Angeli, F. \& Devreux, F. in Scientific Basis for Nuclear Waste Mannagement XXX (eds D. Dunn, C. Poinssot, \& B. Begg) 193-198 (Materials Research Society, 2007).

17. Mansas, C. et al. Drivers of water transport in glass: chemical or topological effect of the glass network? J. Phys. Chem. C. 121, 16201-16215 (2017).

18. Angeli, F., Gaillard, M., Jollivet, P. \& Charpentier, T. Contribution of ${ }^{43}$ Ca MAS NMR for probing the structural configuration of calcium in glass. Chem. Phys. Lett. 440, 324-328 (2007).

19. Utton, C. A. et al. Dissolution of vitrified wastes in a high-pH calcium-rich solution. J. Nucl. Mater. 435, 112-122 (2013).

20. Jantzen, C. M. Durable glass for thousands of years. Int. J. Appl. Glass Sci. 1, 38-62 (2010).

21. Jolivet, J. P., Henry, L. \& Livage, J. De la solution à l'oxyde: condensation des cations en solution aqueuse, chimie de surface des oxydes. (InterEditions / CNRS Editions, 1994).

22. Chave, T., Frugier, P., Gin, S. \& Ayral, A. Glass-water interphase reactivity with calcium rich solutions. Geochim. Cosmochim. Acta 75, 4125-4139 (2011).

23. Nieto, P., Dron, R., Thouvenot, R., Zanni, H. \& Brivot, F. Etude de la transfomation sol-gel du complexe calcium-polysilicate par RMN de ${ }^{43} \mathrm{Ca}$. Comptes Rendus De. I'Academie Des. Sci. - Ser. Il Fasc. B - Mécanique, Phys., Chim., Astron. 320, 485-488 (1995).

24. Rebiscoul, D. et al. Reactive transport processes occurring during nuclear glass alteration in presence of magnetite. Appl. Geochem. 58, 26-37 (2015).

25. Stack, A. G. et al. Pore-size-dependent calcium carbonate precipitation controlled by surface chemistry. Environ. Sci. Technol. 48, 6177-6183 (2014).

26. Mercado-Depierre, S., Angeli, F., Frizon, F. \& Gin, S. Antagonist effects of calcium on borosilicate glass alteration. J. Nucl. Mater. 441, 402-410 (2013).

27. Cunnane, J. C. et al. High.-Lev. Waste borosilicate Glass.: a Compend. Corros. Charact. II, 324 (1994).

28. Jollivet, P., Gin, S. \& Schumacher, S. Forward dissolution rate of silicate glasses of nuclear interest in clay-equilibrated groundwater. Chem. Geol. 330, 207-217 (2012).

29. Caurel, J., Vernaz, E. \& Beaufort, D. in Scientific Basis for Nuclear Waste Management XIII Symposium (eds V. M. Oversby \& P. W. Brown) 309-318 (Mater. Res. Soc, 1990).

30. Gong, W. L. et al. Analytical electron microscopy study of surface layers formed on the French SON68 nuclear waste glass during vapor hydration at $200^{\circ} \mathrm{C}$. J. Nucl. Mater. 254, 249-265 (1998).

31. Ribet, S. \& Gin, S. Role of neoformed phases on the mechanisms controlling the resumption of SON68 glass alteration in alkaline media. J. Nucl. Mater. 324, 152-164 (2004).

32. Friedman, I., Smith, R. L. \& Long, W. D. Hydration of natural glass and formation of perlite. Geol. Soc. Am. Bull. 77, 323-328 (1966).

33. Lee, R. R., Leich, D. A., Tombrello, T. A., Ericson, J. E. \& Friedman, I. Obsidian hydration profile measurements using a nuclear reaction technique. Nature 250, 44-47 (1974).

34. Jezek, P. A. Natural hydration and ion exchange of obsidian: an electron microprobe study. Am. Mineral. 63, 266-273 (1978).

35. Ericson, J. E. in Scientific Basis for Nuclear Waste Management Vol 3, 283-290 (Mater. Res. Soc, 1981).

36. White, A. F. Surface chemistry and dissolution kinetics of glassy rocks at $25^{\circ} \mathrm{C}$. Geochim. Cosmochim. Acta 47, 805-815 (1983).

37. Dal Bianco, B., Bertoncello, R., Milanese, L. \& Barison, S. Glasses on the seabed: surface study of chemical corrosion in sunken Roman Glasses. J. Non-Cryst. Solids 343, 91-100 (2004) 
38. Dal Bianco, B., Bertoncello, R., Milanese, L. \& Barison, S. Glass corrosion across the Alps: a surface study of chemical corrosion of glasses found in marine and ground environnements. Archaeometry 47, 351-360 (2005).

39. Silvestri, A., Molin, G. \& Salviulo, G. Archaeological glass alteration products in marine and land-based environments: morphological, chemical and microtextural characterization. J. Non-Cryst. Solids 351, 1338-1349 (2005).

40. Barbana, F., Bertoncello, R., Milanese, L. \& Sada, C. Alteration and corrosion phenomena in Roman submerged glass fragments. J. Non-Cryst. Solids 337 136-141 (2004).

41. Longinelli, A., Silvestri, A., Molin, G. \& Salviulo, G. 1.8 ka old glass from the Roman ship Julia Felix: glass-water oxygen isotope exchange. Chem. Geol. 211, 335-342 (2004).

42. Collin, M., Fournier, M., Charpentier, T., Moskura, M. \& Gin, S. Impact of alkali on the passivation of silicate glass. npj Mater. Degradation 2, 16 (2018).

43. Depierre, S. Etude des mécanismes d'altération du verre par des eaux cimentaires, Université de Montpellier, Montpellier 2, (2012).

44. Karkhanis, S. N., Bancroft, M. G., Fyfe, W. S. \& Brown, J. D. Leaching behaviour of rhyolite glass. Nature 284, 435-437 (1980).

45. Inagaki, Y. et al. Aqueous alteration of Japanese simulated waste glass P0798 Effects of alteration-phase formation on alteration rate and cesium retention. $J$. Nucl. Mater. 354, 171-184 (2006).

46. Gin, S., Beaudoux, X., Angeli, F., Jegou, C. \& Godon, N. Effect of composition on the short-term and long-term dissolution rates of ten glasses of increasing complexity from 3 to 30 oxides. J. Non-Cryst. Solids 358, 2559-2570 (2012).

47. Aréna, H. Effets cumulatifs et compétitifs des éléments chimiques sur l'altération des verres nucléaires. (Ph-D thesis, Montpellier, 2016).

48. Rajmohan, N., Frugier, P. \& Gin, S. Composition effects on synthetic glass alteration mechanisms: Part 1. Experiments. Chem. Geol. 279, 106-119 (2010).

49. Chave, T., Frugier, P., Ayral, A. \& Gin, S. Solid state diffusion during nuclear glass residual alteration in solution. J. Nucl. Mater. 362, 466-473 (2007)

50. Neeway, J., Abdelouas, A., Grambow, B. \& schumacher, S. Dissolution mechanism of the SON68 refenrence nuclear waste glass: new data in dynamic system in silica saturation conditions. J. Nucl. Mater. 451, 31-37 (2011).

51. Gin, S. et al. The fate of silicon during glass corrosion under alkaline conditions: a mechanistic and kinetic study with the International Simple Glass. Geochim. Cosmochim. Acta 151, 68-85 (2015).
52. Baum, M. The role of nanoconfinement on water properties and specific ion effects on the evolution of porous silica. (Ph-D thesis, Montpellier, 2018).

53. Thien, B., Godon, N., Ballestero, A., Gin, S. \& Ayral, A. The dual effect of Mg on the long-term alteration rate of AVM nuclear waste glasses. J. Nucl. Mater. 427, 297-310 (2012).

54. Debure, M., Frugier, P., De Windt, L. \& Gin, S. Dolomite effect on borosilicate glass alteration. Appl. Geochem. 33, 237-251 (2012).

55. Ohtaki, H. \& Radnai, T. Structure and dynamics of hydrated ions. Chem. Rev. 93, 1157-1204 (1993).

56. Jollivet, J.-P. et al. Zirconium local environment in simplified nuclear glasses altered in basic, neutral or acidic conditions: evidence of a double-layered gel. J. Non-Cryst. Solids 503-504, 268-278 (2019).

57. Jégou, C. Mise en évidence expérimentale des mécanismes limitant l'altération du verre R7T7 en milieu aqueux. Critique et proposition d'évolution du formalisme cinétique., Université des Sciences et Techniques du Languedoc, Montpellier (1998).

58. Gin, S. et al. An international initiative on long-term behavior of high-level nuclear waste glass. Mater. Today 16, 243-248 (2013).

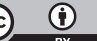

Open Access This article is licensed under a Creative Commons Attribution 4.0 International License, which permits use, sharing, adaptation, distribution and reproduction in any medium or format, as long as you give appropriate credit to the original author(s) and the source, provide a link to the Creative Commons license, and indicate if changes were made. The images or other third party material in this article are included in the article's Creative Commons license, unless indicated otherwise in a credit line to the material. If material is not included in the article's Creative Commons license and your intended use is not permitted by statutory regulation or exceeds the permitted use, you will need to obtain permission directly from the copyright holder. To view a copy of this license, visit http://creativecommons. org/licenses/by/4.0/.

(c) The Author(s) 2019 